\title{
Modernistas em um diner
}

TelêAncona Lopez

0 arquivo de $M$ ário de Andrade, no Instituto de Estudos Brasileiros da Universidade de São Paulo, guarda, entre os cardápios que o escritor preservou, este, de um jantar oferecido por René Thiollier a O lívia Guedes Penteado, em 1925, 7 de maio. Perdão! Trata-se do menu do diner, que distingue a homenageada como "M adame" e designa em francês todas as iguarias de sal sopa, peixe, massa leve recheada (vol au vent) com recheio de fígado de gansos desafortunados, peru à brasileira, presunto de York, salada -; as sobremesas bolo batizado com o nome do amigo distante, o poeta franco-suíço Blaise C endrars, salada de frutas e sorvete. As bebidas são champanhe e licores, estes, assim como o café, para fechar o ágape que confraterniza os modernistas de São Paulo e seus mecenas, no ano da publicação de Pau Brasil, de 0 swald de Andrade. 0 nome "M ario de Andrade", a tinta preta, no alto, indica a organização dos convivas à mesa; 0 apuro gráfico do cardápio; a mansão da avenida Paulista que tem por nome "Villa Fortunata" e se mostra em fotografia trabalhada pelo estúdio Stern, de Paris, testemunham o vínculo de certos representantes da elite social e econômica com a renovação das artes e das letras. O s três mecenas do modernismo paulistano estão presentes: 0 anfitrião, dona O lívia Guedes Penteado e Paulo Prado. Thiollier, contista de 0 senhor dom Torres (1921), e o editor da Revista do Brasil haviam se empenhado para a realização da Semana de Arte M oderna, em 1922, e D ona O lívia, em seu salão nos Campos Elíseos, destacava-se como a Senhora das Artes, segundo a historiadora $D$ enise $M$ attar. $O$ s três assinam o verso do cartão, assim como Tarsila do Amaral, O swald de Andrade (como "Pau Brasil"), Guilherme de Almeida e outros presentes. M ário de Andrade constrói seu souvenir, desperto para o relato da $\mathrm{H}$ istória nos documentos do cotidiano.

Em abril do ano anterior, na viagem a M inas Gerais, que empreendera com D. O lívia, Tarsila, O swald e o filho dele, N onê, Paulo Prado, René Thiollier, G ofredo da Silva Telles e Blaise Cendrars, viagem na qual nascera a estética Pau Brasil, M ário de Andrade copiara, para seu arquivo, os dados pessoais deixados 
pelos excursionistas no $\mathrm{H}$ otel $\mathrm{M}$ acedo, em São João $\mathrm{D}$ el Rei. Eis o registro impregnado do "claro riso dos modernos", unindo mecenas, pintora e poetas: “D. O lívia Guedes Penteado, solteira, photographer, anglaise, London. D. Tarsila do Amaral, solteira, dentista, americana, Chicago. Dr. René Thiollier, casado, pianista, russo, Rio. Blaise Cendrars, solteiro, violinista, allemand, Berlin. M ário de Andrade, solteiro, fazendeiro, negro, Bahia. 0 swald de Andrade Filho, solteiro, escrittore, suíço". 
Pro-Posições, v. 19, n. 1 (55) - jan./abr. 2008

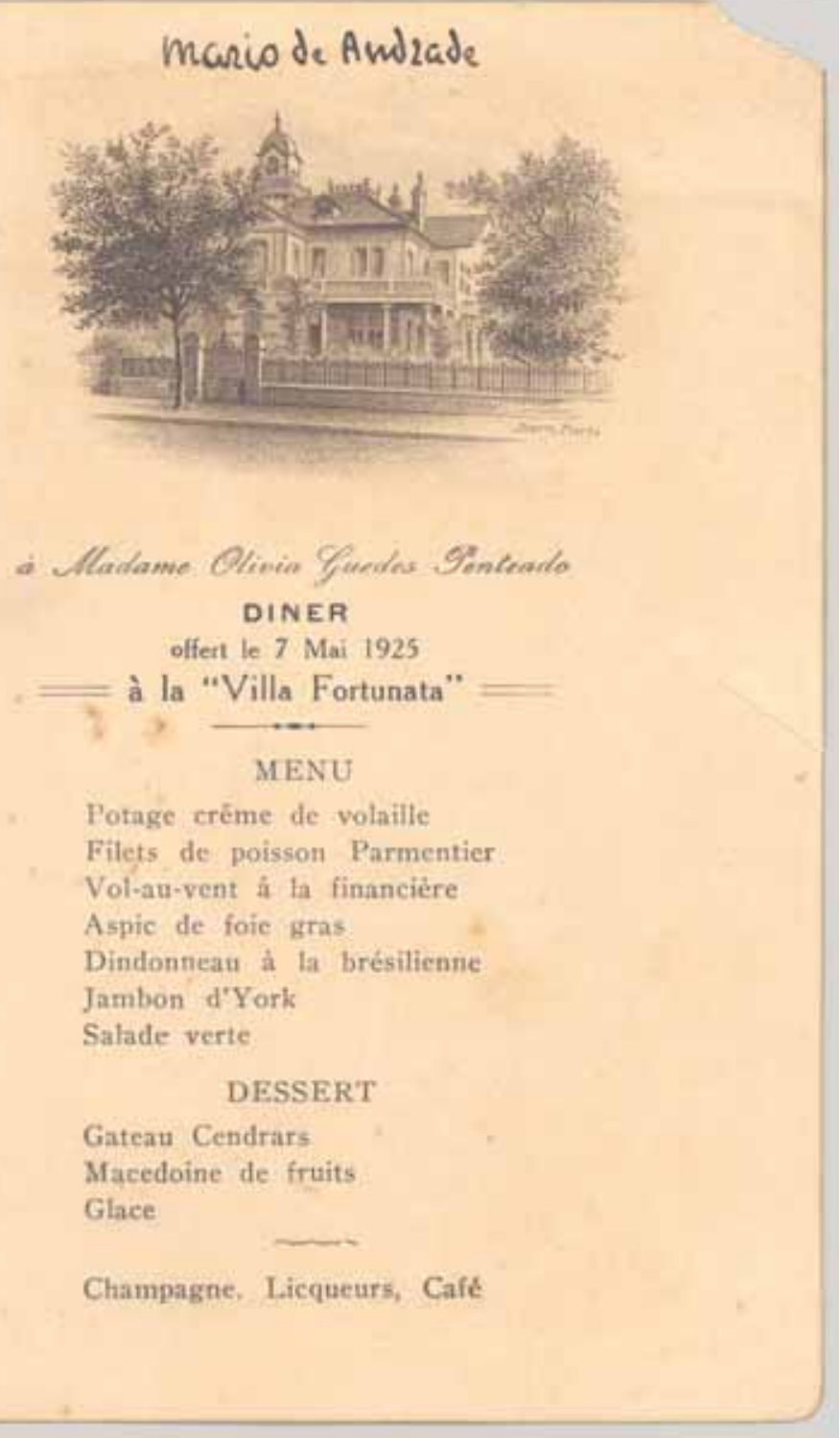

Cardápio (15x10 cm). São Paulo, 7 maio 1925. (frente) Arquivo Mário de Andrade, IEB-USP 
Pro-Posições, v. 19, n. 1 (55) - jan./abr. 2008

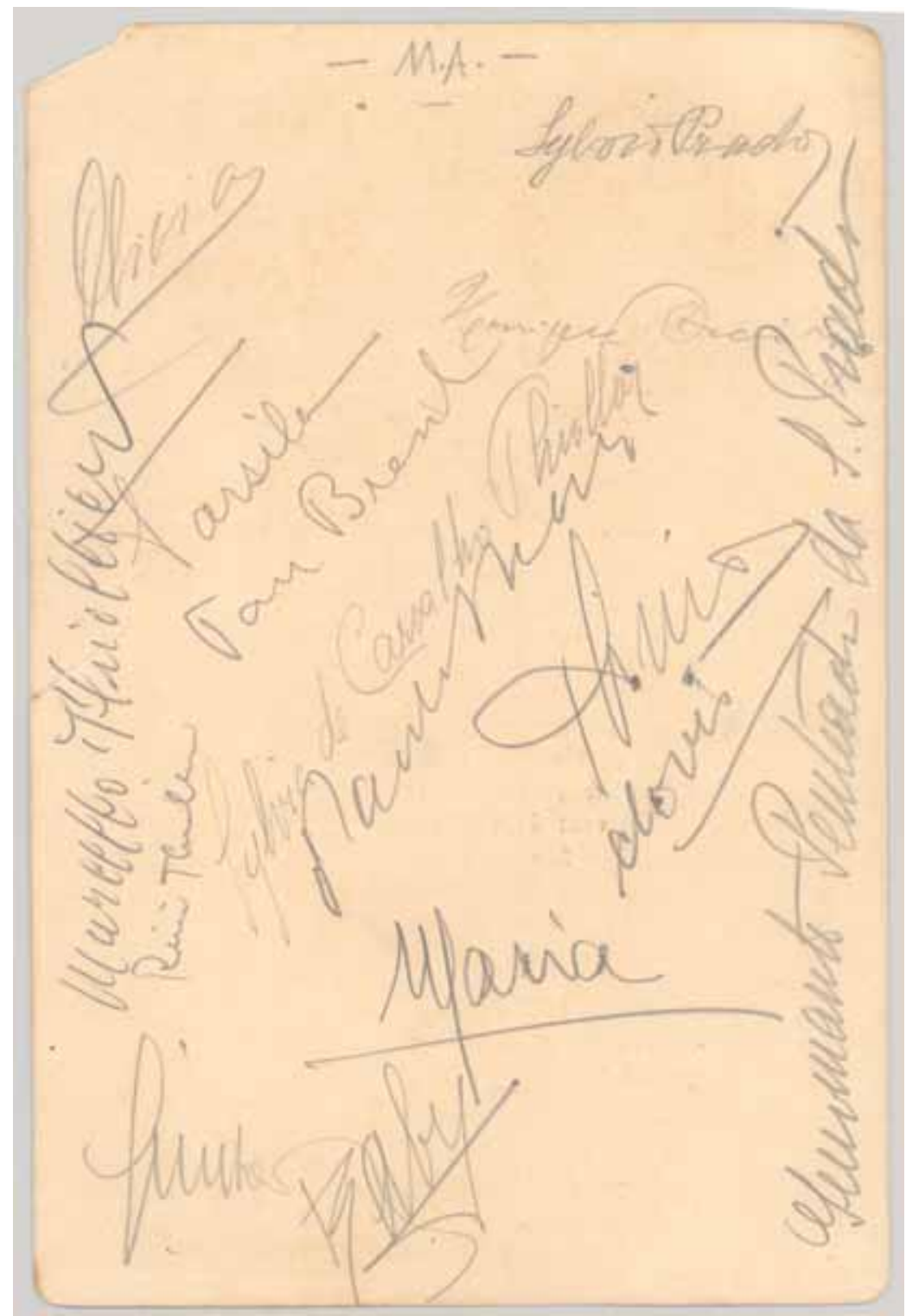

Cardápio (15x10 cm). São Paulo, 7 maio 1925. (verso) Arquivo Mário de Andrade, IEB-USP 